\title{
HEART BLOCK FOLLOWING DIPHTHERIA
}

\author{
BY \\ D. G. LEYS \\ From the Royal Northern Infirmary, Inverness \\ Received August 16, 1944
}

In 1943 when reporting a case of congenital heart block with dextrocardia (Leys, 1943) I discussed the differential diagnosis of acquired and congenital heart block. It was remarked that complete heart block due to diphtheria (and probably other infections also) was almost always fatal, and that nearly all cases of complete heart block in children and young adults were congenital. Fishberg (1940) with his very extensive practice, had seen only one patient surviving the appearance of complete heart block in diphtheria: he referred to a study by Stechner in 1928 of 19 cases, all fatal, and to a study by Jones and White in 1927 of 100 patients after severe diphtheria, none of whom had evidence of heart disease at the time of their examination. Hoskin (1926) found various minor post-diphtheritic cardiographic changes in 16 cases following severe attacks, but found no conduction defects.

I now report a case of complete dissociation of auricle and ventricle in a married woman of 25 who had severe diphtheria at the age of 10 with palatal and ocular palsies. She reports that her heart was said to have been affected at that time, and that it was later remarked to her, when she had cerebrospinal fever at the age of 22 , that she had a slow pulse. No comment on her pulse rate was made when she had appendicectomy at a cottage hospital at the age of 18 .

She was referred to the Royal Northern Infirmary, Inverness, because of attacks of syncope; these had began to appear shortly after an illness in which she had sore throat and joint pains. She remained in bed for only a few days. A similar illness had occurred two years previously. The attacks consisted of a choking sensation in the throat, pain and a tight sensation in the chest, followed by transient loss of consciousness, and later by vomiting.

The heart rate at rest is either 36 or 48; other rates are not found. After exercise it rises

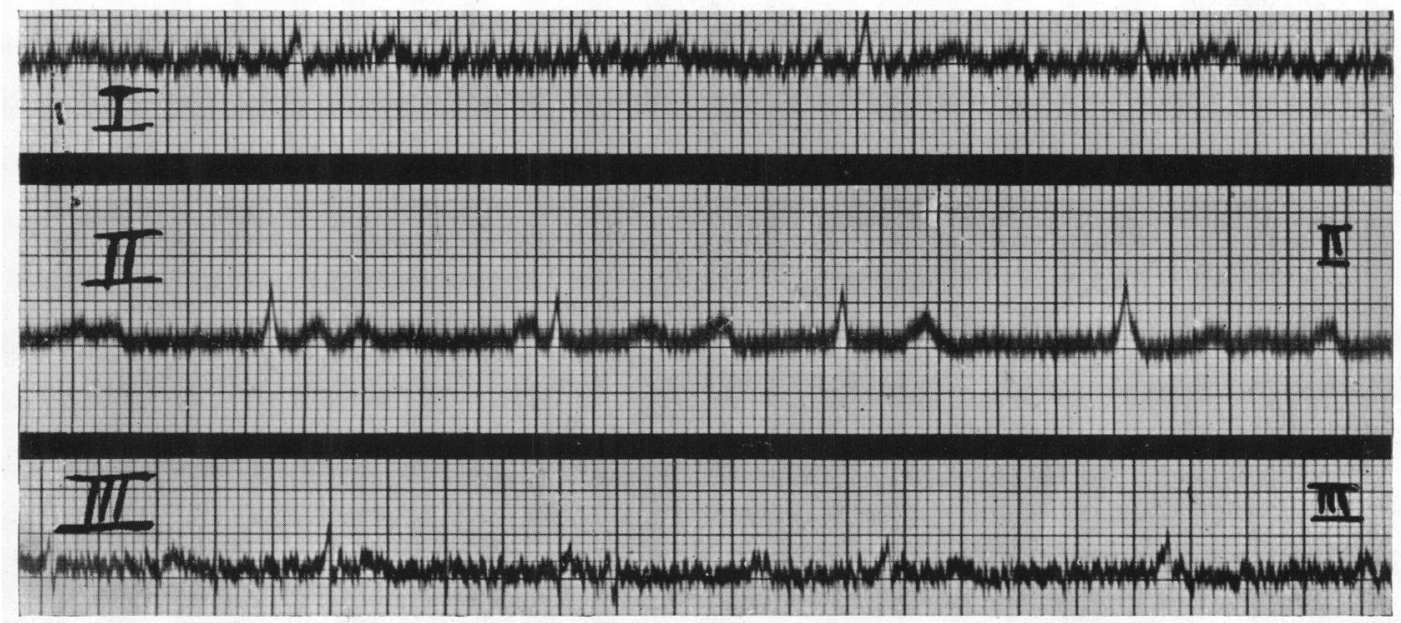

FIG. 1.-Electrocardiogram, showing complete heart block: auricle, 86 ; ventricle, 60 a minute; after exercise. 


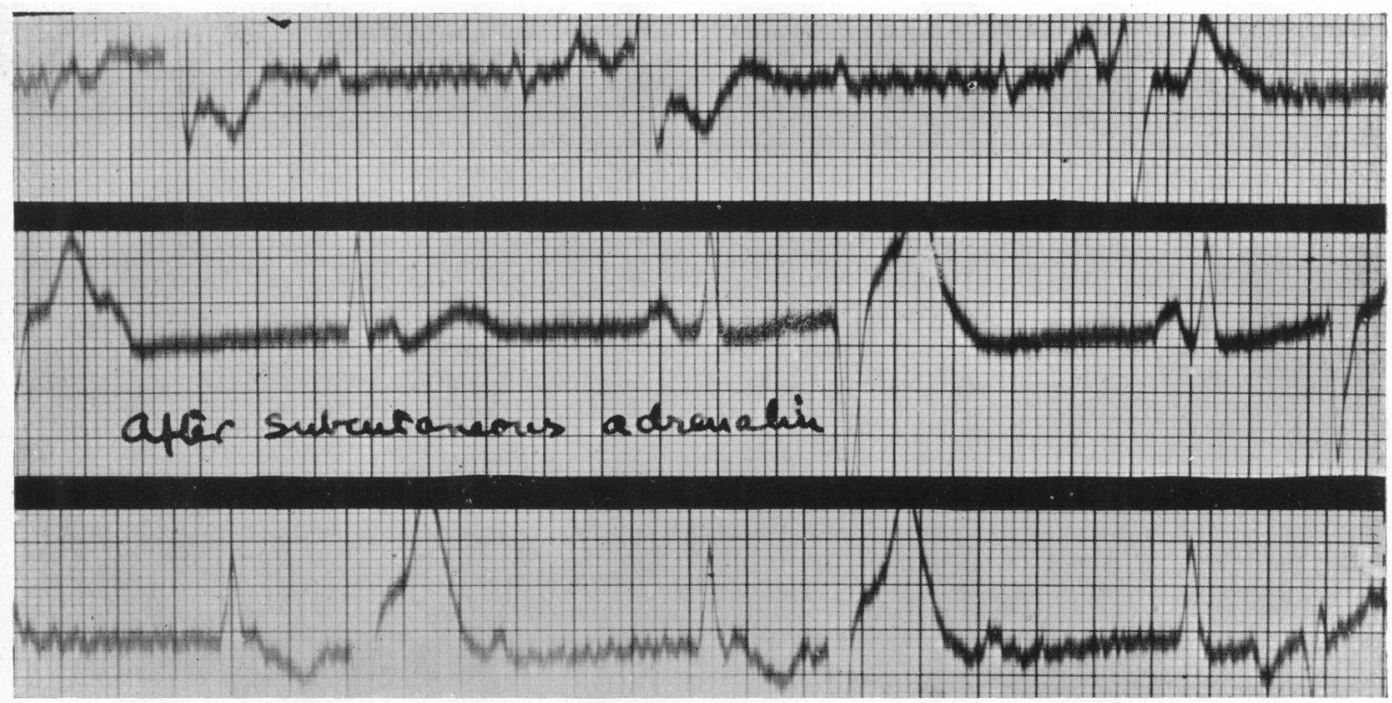

FIG. 2.-After subcutaneous injection of adrenalin showing frequent ventricular extrasystoles: auricular rate about 75 ; ventricular rate about 48 when no extrasystoles.

to 60. It is not influenced by subcutaneous injection of $1 / 100$ of a grain of atropine sulphate. Ventricular extrasystoles appear after exercise and after subcutaneous injection of adrenalin. These extrasystoles alternate with regular beats for 10 to 20 cycles at a time. X-ray screening shows slight enlargement of the left side of the heart. Clinically, the heart does not appear enlarged, with the apex beat three and a half inches from the midline. There are no murmurs. The blood pressure is $150 / 90$. The pulse is dicrotic. The cardiogram shows complete dissociation of auricle and ventricle, but otherwise is normal except for the appearance of the ventricular extrasystoles. These are not present when she is at rest. There is a complete absence of all tendon jerks throughout the body.

\section{SUMMARY}

The evidence for this case of complete heart block being due to diphtheria is:

(1) that she had severe diphtheria with neuritis at the age of 10 years;

(2) that subsequently a slow pulse was reported at the age of 22 years; and

(3) that she has complete absence of all tendon jerks without other evidence of nervous system disease.

\section{REFERENCES}

Leys, D. G. (1943). Brit. Heart J., 3, 8.

Fishberg, A. M. (1940). Heart Failure, p. 590.

Hoskin, J. (1926). Lancet, 1, 1141. 